\title{
A Functional Anatomy of Anticipatory Anxiety
}

\author{
Phyllis Chua,*,† Michael Krams,* I van Toni,* Richard Passingham*, and Raymond Dolan,*,§ \\ *Wel Icome Department of Cognitive Neurol ogy, Institute of Neurol ogy, Queen Square, London WC1N 3BG, United Kingdom; \\ †Department of Psychiatry, University of Mel bourne, Melbourne, Australia; ¥Department of Psychol ogy, Oxford University, Oxford, \\ United Kingdom; and §Academic Department of Psychiatry, Royal FreeHospital School of Medicine, London NW3, United Kingdom
}

Received J une 22, 1998

Anticipatory anxiety is a complex combination of a future-oriented cognitive state, negative affect, and autonomic arousal. A dual-task paradigm of anticipation of electric shocks and a motor-learning task was used to examine the changes in neural patterns of activation associated with modulation of the cognitive state in anxiety by a distracting motor task. We used positron emission tomography (PET) and ${ }^{15} \mathrm{O}$-water to measure regional cerebral blood flow ( $\mathrm{rcbf}$ ) in 10 healthy male volunteers. A $2 \times 2$ factorial design(shock vs no shock) $\times$ (low vs high distraction) was used with three scans per condition. Twelve PET scans were performed on each subject. In six of these scans, subjects were given electric shocks. In all scans, subjects also simultaneously performed a motor repetition (low distraction) or learning (high distraction) task. Galvanic skin conductance (GSR), Spielberger State and Trait Anxiety Inventory (STAI), and selfreport data were also collected. In comparisons between the shock and no-shock conditions, the main finding was of increased $\mathrm{rcbf}$ in the left insula $(-38,8,8)$ $(z=4.85, P<0.05$ corrected $)$ and a homologous area in the right insula at a lower threshold $(z=3.20, P=0.001$ uncorrected). Other areas activated were the right superior temporal sulcus, left fusiform, and left anterior cingulate. Using the STAI-state scores as a covariate of interest, significant correlations with rCBF were seen in the left or bitofrontal cortex, left insula, and left anterior cingulate cortex. There was no significant distraction effect as measured by the STAI, self-report, GSR response or interactional analysis of the PET data. These findings support the role of paralimbic structures as neural substrates of anticipatory anxiety. The failure to demonstrate behavioral and neurophysiological changes with the distractor task may reflect the modest increases in anxiety with the shock, the relatively simple distractor task, and small sample size. 1999Academic Press

\section{INTRODUCTION}

Anxiety is best conceptualized as a future-oriented cognitive-affective-somatic state, the prominant feature being "a sense of uncontrollability focused on possible future threat, danger, or other upcoming, potentially negative events" (Barlow et al., 1996). Associated with this is a negative affective state of a sense of fear (Izard and Youngstrom, 1996), hel plessness (Barlow et al., 1996), and accompanying somatic components of central nervous system arousal. Various models of anxiety have attempted to explain the neuropsychological mechanisms (Barlow et al., 1996; Gray and McNaughton, 1996) and neuroanatomical substrates of anxiety. For example, functional neuroimaging techniques have demonstrated that the neural substrates of emotions are not confined to one specific "emotional" area of the brain but consist of complex interactions between different brain structures. It is noteworthy that most of these studies have focussed on anxiety disorders such as simple phobia (F redrickson et al., 1993; Mountz et al., 1989; O'Carroll et al., 1993; Wik et al., 1993; Rauch et al., 1995), panic disorder (Reiman et al., 1984; Reiman, 1987, Reiman et al., 1989; Nordahl et al., 1990), and obsessive-compulsive (Baxter et al., 1987a,b, 1988, 1992; Swedo et al., 1989; Horwitz et al., 1991; Nordahl et al., 1989; Martinot et al., 1990; Azari et al., 1993; Perani et al., 1995; McGuire et al., 1994; Rauch et al., 1994) disorder rather than in anxiety in normal individuals.

A common el ement in anxiogenic stimuli in studies is the production of an unpleasant sensation such as pain (Reiman et al., 1989; Rodriguez et al., 1989). The aim of this study was to investigate one of the most basic forms of anxiety, namely anticipatory anxiety which is experienced by normal individuals and which may play a role in anxiety disorders such as panic disorder (Barlow et al., 1996). We applied several el ectric shocks to the hand to induce a state of anticipatory anxiety and manipulated the subject's attention to these anxiogenic 
stimuli using a distracting motor-learning task. Attentional focus in exposure-based treatments for fear and anxiety has been hypothesized to interact with the mechanisms for fear reduction (Craske and Street, 1991), although controversy remains in regards to the direction of fear modification and the immediate versus long-term effects. Specifically, a dual-task paradigm of electric shocks and motor-learning task can potentially tease apart the neural substrates involved in cognitive aspects of anxiety (i.e., attention), from those responsible for affective and physiological components. A nonscanning pilot study prior to the current study had indicated that this type of motor-learning task can reduce subjective anxiety.

\section{METHODS}

\section{Subjects}

The subjects were 10 normal healthy male vol unteers with a mean age of 30.4 years (range $=21-40$ years). All were right handed. None of the subjects had a history of major neurological or psychiatric disorders including substance abuse. None were using psychotropic medications. The study was approved by the Ethics Committee of the Institute of Neurology. Each subject gave informed consent.

\section{Experimental Design}

All subjects underwent a PET (Positron Emission Tomography) and MRI (Magnetic Resonance I maging) scan. The MRI scan was for the purpose of anatomical localization of PET data after coregistration with the data. For the PET scan, the dual-task paradigm consisted of electric shocks to induce anticipatory anxiety and the use of a motor-learning task as the distractor from the anxiety. The factorial design consisted of four conditions: (1) shock and motor learning, (2) no shock and no motor learning, (3) shock and no motor learning, and (4) no shock and no motor learning. Twel ve sequential scans using ${ }^{15} \mathrm{O}$-water as a tracer and measure of regional cerebral blood flow (rCBF) were performed for each subject. There were three scans per condition and the four conditions were randomized within and between subjects across the 12 scans.

In the shock conditions, electric shocks wereadministered to the dorsal aspect of the right hand. An electrical stimulator box delivered variable voltage and current to the subject within a safety limit. Two Neuroline disposable neurology el ectrodes with gel and adhesive were attached to the dorsal aspect of the subjects right hand. The size of the delivered shock was determined individually for each subject. Prior to each scan, subjects were given electric shocks to determine the highest threshold which they could tolerate and the electrical stimulator was set using this value as the minimum setting. During the PET scan sessions, electric shocks were delivered randomly prior to the onset of the PET scanning interval such that the subject was unable to predict when the next electric shock was going to be delivered. No electric shocks were delivered during the scanning window. The background color of the computer monitor screen was either red or blue to warn the subject whether there were going to be shocks given during the task or not. A red screen col or indicated that shocks would be given at any time and a blue screen color indicated that shocks would not be given. Subjects were shown this in thetraining session prior to thePET scan.

A motor learning task was used as a distractor task. In thelearning condition, the subject had to learn a new sequence of key presses by trial and error. The keypad consisted of four keypresses corresponding to the four fingers of the right hand. The movements were paced by the computer screen at a rate of one every $2.5 \mathrm{~s}$. A circle appearing on the computer screen every $2.5 \mathrm{~s}$ prompted the subject to make the next finger movement. The subject would try to identify the first movement. If their response was correct, a tick would appear. If it was incorrect, a cross would appear instead. This method of trial and error continued until the subject learned an eight-movement sequence. When a sequence was learned, subjects were then instructed that they would be given a new sequence to learn. There were different sequences for the six learning conditions for each subject. Subjects were specifically told not to remember the sequence by naming or numbering the digits.

In the no motor-learning condition, subjects performed a repetitive sequence which was learned prior to the scans. The eight finger presses for the repetitive no motor-learning sequence consisted of index, middle, ring, little, index, middle, ring, and little. The movements were still paced by a circle on the computer screen at the same rate of $2.5 \mathrm{~s}$. Subjects still received a feedback of a tick for a correct response and a cross for an incorrect response. Subjects were taught both the motor learning and no motor learning tasks prior to the scans.

Galvanic skin response (GSR) was measured using Neuroscan and a skin conductance coupler providing a constant $0.5 \mathrm{~V}$ across electrodes. The GSR was measured using two electrodes attached to the palmar aspect of the left index and left middle fingers. Prior to the placement of the electrodes, the fingers were wiped clean with distilled water and dried. Data was collected prior to the onset of PET scanning and finished after the PET scan ended. The timing of the delivered shocks were manually marked onto the Neuroscan data.

Prior to the PET scans, subjects were administered the Spiel berger State and Trait Anxiety (STAI ) questionnaires and asked to give a rating of their anxiety on a 
scale from 0 to 100. An intravenous cannula was inserted into the left cubital fossa and electrodes were attached to the dorsal aspect of the right hand. The PET scans were performed in a darkened room with the subjects lying supine. Both arms were supported by arm rests. The keypad was placed within comfortable reach of the right hand and secured to the right arm rest. Subjects received a total of $9 \mathrm{mCi}$ over $20 \mathrm{~s}$ through an automatic delivery system. After each PET scan, subjects were administered the STAI-state questionnaire and asked to give a rating of their anxiety on a scale from 0 to 100. A debriefing session after the last scan confirmed that subjects were not able to predict when they were going to be given the next electric shock.

\section{PET and MRI Data Acquisition}

A Siemens/CTI ECAT EXACT HR + PET scanner operating in high sensitivity $3 \mathrm{D}$ mode was used. The transaxial field of view was $15.5 \mathrm{~cm}$. The scanner was coordinated with the automated ${ }^{15} \mathrm{O}$-water delivery system and was activated when counts in the field of view reached thirty thousand counts per second (cps). Theactivation frame was $90 \mathrm{~s}$. The scanner operated on an 8-min cycle from the beginning of one scan to the next. I mages were reconstructed into 63 planes using a Hanning filter. This resulted in a 6.4-mm transaxial and 5.7-mm axial resolution.

The structural MRI scan was obtained using a Siemens/Magneton vision scanner operating at 2 Tesla and a maximum gradient field strength of 25 Tesla per meter. A Magnetized Prepared-Rapidly Acquired Gradient Echo (MPRAGE) volume acquisition T1-weighted sequence was used to obtain good anatomical details. I nplane resolution was $1 \mathrm{~mm}$ and slice thickness was $1.5 \mathrm{~mm}$. The sequence took $7.5 \mathrm{~min}$. Images were acquired in the axial planes.

\section{Data Analysis}

The data was processed and analyzed using Statistical Parametric Mapping (SPM) 96 software (Wellcome Department of Neurology, London) implemented in Matlab (Mathworks, Sherborn, MA). The PET scans were realigned to correct for involuntary movements between scans. The mean realigned PET scan was coregistered with the structural MRI scan. The realigned PET and coregistered structural MRI scans were then transformed through the process of normalization into standard stereotactic space. The PET images were then filtered with a low-pass Gaussian filter at $12 \mathrm{~mm}$. Differences in global blood flow were adjusted to a global mean of $50 \mathrm{ml} / \mathrm{dl} / \mathrm{min}$ by using subject-specific analysis of covariance. Blood flow changes between conditions were assessed using the $t$ statistic. The resultant SPM(t) map identified areas of statistically significant blood flow changes as a result of the differences in rcbf between the different conditions. The localization of the maxima of the SPM(t) statistics are identified in terms of Talairach and Tournaux (1988) coordinates. A mean MRI of the 10 subjects was used also as a template to improve the localization of these activations. Two separate analyses were also carried out using the STAI scores and the rCBF value from the left insula as covariates of interest in the analysis of the PET data. In the latter analysis, the rCBF values in the left insula were used to examine whether the activity in the left insula predicted responses in other brain regions, specifically the amygdala, under the condition of shock versus no shock.

The GSR data was analyzed using Neuroscan and Acknowledge software. The GSR data was edited using the Edit module in the Neuroscan software. The data obtained in the time interval from the onset of GSR recording to $4 \mathrm{~s}$ from the administration of the last shock was collected for further analysis by the Acknowledge software. In the conditions where no shocks were delivered, the mean time interval of relevant data collection, as defined above, was calculated for each subject and a similar time interval of GSR data collection was chosen for the no shock conditions. Using the Acknowledge software, the range, i.e., from the minimum to the maximum peaks, was calculated for each of the scans.

\section{RESULTS}

\section{Behavioral Self-Report Measures}

The findings from the STAI-state scores indicated that although the increases in the scores were modest, the averaged group STAI-state score was significantly higher in the shock $(50.5 \pm 12.3)$ compared to no shock conditions $(35.5 \pm 6.6)(P<0.001))$. The distraction effect, whereby the STAI scores were one standard deviation lower in the shock and motor learning condition compared to the shock and no motor learning conditions, was seen in only two subjects. Four other subjects showed a degree of distraction but the difference in the scores did not reach one standard deviation significance.

In the self-report scale of 100,7 of 10 subjects had higher scores in the shock state compared to the no shock state at a significance level $P<0.05$; four of these achieved differences in the scores at $P<0.001$. Three subjects were distracted by the motor learning task as evident in the difference of one standard deviation in their self-report anxiety scores. One other subject demonstrated a small level of distraction but did not reach one standard deviation significance. 


\section{GSR Measures}

GSR was collected for 9 of the 10 subjects. The GSR peak to peak range (units-mSiemens) was greater in the shock compared to the no shock conditions in eight of the subjects, the difference reaching a significance level of $\mathrm{P}<0.05$ in five of the eight subjects. There was no significant effect of distraction evident in the GSR data.

\section{PET Data}

Analysis of the data comprised results from 10 subjects to demonstrate the main effect of anticipatory anxiety. A further analysis of nine subjects was undertaken whereby the STAI scores were used as covariates of interest. One subject was excluded as he did not have balanced number of scans.

Main effects of shock. The main effect of shock was determined by comparison of the neural responsein the conditions where the subjects were expecting compared to not expecting shock (Fig. 1). In the shock condition, the sole area where there is increased neural activity, which survived correction, was in the left insula ( $z=4.85, P<0.05$ corrected). A homologous area in the right insula also showed a significant increase in neural response at a lower threshold $(z=3.20$, $P=0.001$ uncorrected). The rCBF data for the pixel of maximal significance in the left insula for each of the four conditions is shown in Fig. 1. A number of other areas which did not survive stringent correction are presented for descriptive purpose in Table 1. These areas comprise the right superior temporal sulcus, left anterior cingulate, and left fusiform gyrus.

Main effects of learning. The main effect of learning was determined by contrasting the motor learning with the no motor learning conditions. The areas of activation comprised the prefrontal cortex bilaterally, left cingulate cortex, left premotor cortex, bilateral insula, bilateral parietal cortex, left thalamus, and bilateral cerebellum. (Table 2).

\section{STAI as a Covariate of I nterest}

To determine the relationship between the presence of anticipatory anxiety and the underlying neural response, the anxiety scores on the STAI were used as covariates of interest. Nine subjects were used in this analysis as one subject did not have an equal number of scans across all four conditions. The regions which showed significant covariance at a significant level of $\mathrm{P}<0.001$ (uncorrected) included the left insula, left
TABLE 1

Coordinates of the Pixels Where the Most Significant Differences in rcbf Were I dentified at a Threshold of $\mathrm{P}=0.001$ for Shock Conditions in Ten Subjects

\begin{tabular}{lcc}
\hline \multicolumn{1}{c}{ Area activated } & $\begin{array}{c}\text { Talairach } \\
\text { coordinates } \\
\text { of peak activation }\end{array}$ & $\begin{array}{c}\text { Z score } \\
\text { of peak } \\
\text { activation }\end{array}$ \\
\hline Insula (L) & $-38,8,8$ & 4.85 \\
Superior temporal sulcus (R) & $58,-48,26$ & 3.41 \\
Fusiform (L) & $-42,-16,-30$ & 3.34 \\
Anterior cingulate (L) & $-8,40,16$ & 3.42 \\
\hline
\end{tabular}

Note. The coordinates refer to the stereotaxic atlas of Talairach and Tournoux (Talairach and Tournaux, 1988). Thez score is a measure of the degree of significance of the difference and is the number of standard deviations from the mean $t$ value in the (t) statistical map of the t value for the most significant pixel in the plane. L, left. R, right.

orbitofrontal, left inferior frontal gyrus, and left anterior cingulate (Table 3). The SPM (t) map of the contrast and the rCBF for the left orbitofrontal cortex is shown in Fig. 2.

\section{Psychophysiological Interaction with the Left I nsula}

There was no evidence that activity in the left insula predicted activity in the amygdala in the context of shock compared to the no shock condition.

\section{Effect of Distraction}

For the 10 subjects, no areas survived stringent correction in the analysis for the interaction effects of shock with and without motor learning at a threshold of $\mathrm{P}<0.001$.

\section{DISCUSSION}

The main result from the study is that anticipatory anxiety induced by the expectancy of electric shocks is associated with increased neural activity in the left insula, right temporal sulcus, left fusiform, and left anterior cingulate cortex. When STAI scores are used as a covariate of interest, the significant areas of increased activity are in the left orbitofrontal cortex, left insula, and left anterior cingulate cortex. Interactional analysis of shock and learning was used to tease out the effect of distraction (i.e., which regions had greater activity during the shock and learning conditions compared to the shock and nolearning conditions) but failed to demonstrate an effect. This is re-

FIG. 1. Statistical Parametric Map demonstrating significant changes in cerebral blood flow between Shock and No Shock conditions at a height threshold of $p=0.001$ for the 10 subjects. $\mathrm{rCBF}$ in the left insula for the 10 subjects in the shock condition at a threshold of $p=0.001$

FI G. 2. Statistical Parametric Map demonstrating significant changes in cerebral blood flow between Shock and No Shock conditions at a height threshold of $p=0.001$, using STAI as a covariate of interest. rCBF in the left orbitofrontal cortex. 


\section{transverse}

Sagittal

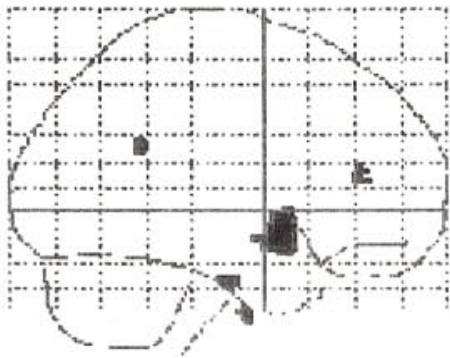

Coronal

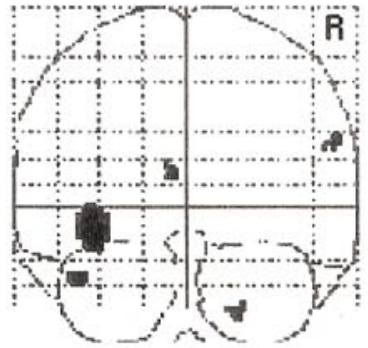

Sagittal

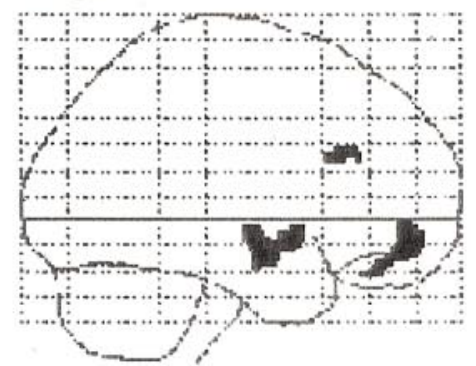

Coronal

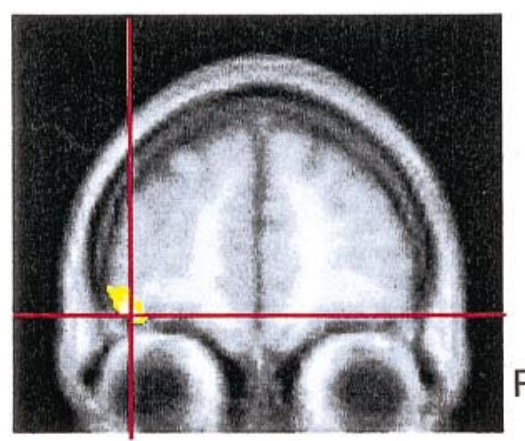

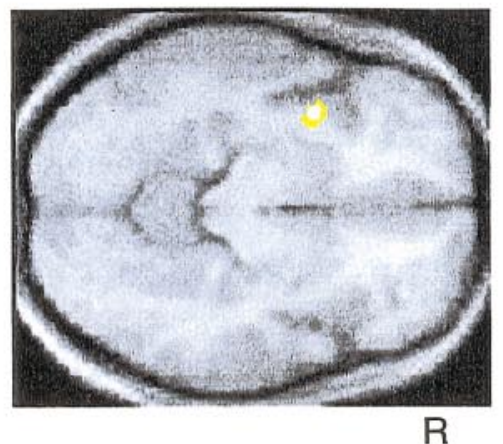

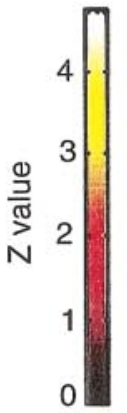

$\mathrm{R}$

$Z=4.85, p=0.000(0.026$ corrected $)$

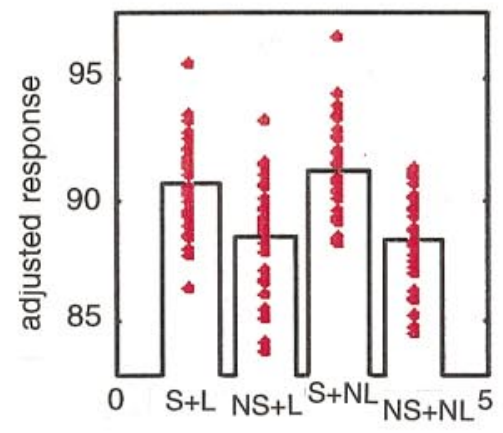

transverse
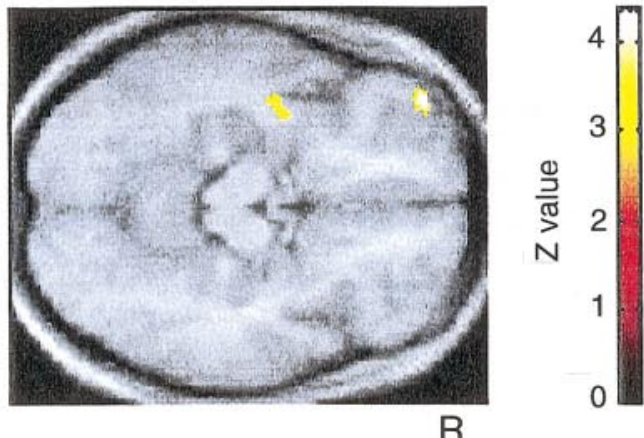

R

$Z=4.47, p=0.000(0.122$ corrected $)$

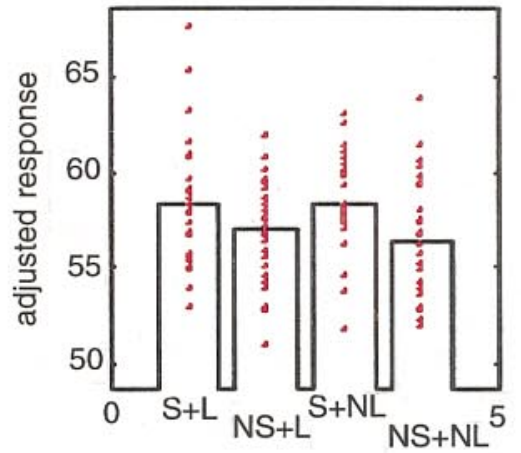




\section{TABLE 2}

Coordinates of the Pixels Where the Most Significant Differences in rcbf Were I dentified at a Threshold of $\mathrm{P}=0.001$ for Learning vs No Learning Conditions in Learning and Nonlearning Environments

\begin{tabular}{lcc}
\hline & $\begin{array}{c}\text { Talairach } \\
\text { coordinates } \\
\text { Area activated }\end{array}$ & $\begin{array}{c}\text { Z score } \\
\text { of peak } \\
\text { activation }\end{array}$ \\
\hline Prefrontal cortex & & \\
Orbitofrontal (L) & $-32,60,-10$ & 4.84 \\
Orbitofrontal (R) & $34,60,-4$ & 5.27 \\
Superior frontal (R) & $28,-2,66$ & 4.11 \\
Middle frontal (L) & $-48,22,32$ & 4.50 \\
Middlefrontal (R) & $40,30,32$ & 4.21 \\
Inferior frontal (L) & $-44,48,16$ & 4.18 \\
Inferior frontal (R) & $56,12,20$ & 4.56 \\
Cingulate cortex & $-14,8,50$ & \\
Anterior (L) & $-24,-6,46$ & 5.02 \\
Premotor cortex (L) & $-46,-2,34$ & 5.17 \\
Precentral (L) & $48,4,34$ & 4.83 \\
Precentral (R) & $-68,-4,26$ & 4.03 \\
Postcentral (L) & $38,22,0$ & 3.59 \\
Insula (R) & $-38,18,2$ & 5.25 \\
Insula (L) & & 3.71 \\
Parietal cortex & $-44,-36,40$ & \\
Intraparietal sulcus (L) & $36,-60,46$ & 6.75 \\
Intraparietal sulcus (R) & $-14,-72,58$ & 5.72 \\
Superior parietal gyrus (L) & $10,-74,52$ & 6.26 \\
Superior parietal gyrus (R) & $-20,-20,6$ & 6.30 \\
Thalamus (L) & $-32,-56,-30$ & 3.32 \\
Cerebellum & $36,-68,-26$ & 5.76 \\
Cortex (L) & $-6,-76,-26$ & 4.78 \\
Cortex (R) & & 3.37 \\
Vermis (L) & & \\
Vermis (R) & & \\
\hline & & \\
\hline
\end{tabular}

Note L, left. R, right.

flected by the lack of significant distraction as measured by the STAI, self-report anxiety, and GSR response. There was no evidence of context-dependent interactions between the left insula and amygdala under the condition of shock compared to no shock. The results from the main effect of the motor learning is similar to those in previous studies of motor learning (J ueptner et al., 1997).

These findings on anticipatory anxiety differ in some respects from those in previous studies. In a similar PET study, Reiman et al. (1989) used anticipation of a painful electric shock to induce anticipatory anxiety and found significant increases in the rCBF in bilateral temporal poles. Although this finding was not without controversy (Drevets et al ., 1992), the temporal pole has been implicated in other studies on anxiety (Fredrickson et al., 1993; Wik et al., 1993; Rauch et al., 1995; Fredrikson et al., 1995). The subjects in Reiman et al.'s (1989) study were scanned before they were given any shocks, unlike the current study where they were scanned after receiving shocks and consequently probably had greater anticipatory anxiety. Rodriguez et al.
TABLE 3

Coordinates of the Pixels Where the Most Significant Differences in rcbf Were I dentified at a Threshold of $\mathrm{P}=0.001$ for Shock vs No Shock Conditions Using the STAI as a Covariate of I nterest

\begin{tabular}{llc}
\hline \multicolumn{1}{c}{ Area activated } & $\begin{array}{c}\text { Talairach } \\
\text { coordinates } \\
\text { of peak activation }\end{array}$ & $\begin{array}{c}\text { Z score } \\
\text { of peak } \\
\text { activation }\end{array}$ \\
\hline Prefrontal cortex & & \\
$\quad$ Inferior frontal (L) & $-42,52,-12$ & 4.47 \\
$\quad$ Orbitofrontal (L) & $-40,44,-18$ & 3.63 \\
Insula (L) & $-40,-6,-12$ & 4.00 \\
Anterior Cingulate (L) & $-12,28,26$ & 3.50 \\
\hline
\end{tabular}

Note L, left. R, right.

found a negative correlation between rCBF as measured by Xenon-133 and anxiety measures (Rodriguez et al., 1989) when the insertion of an intravenous line was used as a means of inducing anxiety. A similar relationship between regional cer ebral glucose metabolism (CMRglu) and anxiety has been noted in previous studies (Gur et al., 1987; Reivich et al., 1984). Performance on a verbal analogy task was positively correlated with the rCBF as measured with Xenon-133, both of which had an inverted-U relationship with the level of anxiety in a later study by Gur et al. (1988). Benkel fat et al . (1995) used a bolus injection of chol ecystokinin tetrapeptide to elicit an anxiogenic response and found rcbf increases in the anterior cingulate, claustrum-insular-amgydale region, and cerebellar vermis.

Our main findings in the anticipatory anxiety conditions are consistent with current views on the neural substrates of anxiety. Rauch et al. (1997) reported on data pooled from three PET studies on three different anxiety disorders-simple phobia, obsessive-compulsive disorder, and posttraumatic stress disorder. Using symptom provocation paradigms specific to each disorder, common areas of activation across the three anxiety disorders were in the right posterior medial orbitofrontal cortex, bilateral insular cortex, bilateral lenticulate nuclei, and bilateral brainstem. In our study, the left insula and left anterior cingulate cortex were common to the effect of shock versus no shock and when the STAI scores were used as a covariate of interest emphasizing their role in the mediation of anxiety.

These areas of the insula, lateral orbitofrontal cortex, and cingulate cortex that we identify constitute what is termed paralimbic cortex where there is transition from more rudimentary allocortex to more complex granular isocortex (Mesulam and Mufson, 1982). The juxtaposition of these structures between the neocortex and limbic areas of the brain, and its architecture, are in keeping with the view that one of the functions of the 
paralimbic structures is to integrate the internal and external milieu (Mesulam and Mufson, 1982). In this regard, the insula has been described as a limbic integration cortex (Augustine, 1996). The insula has connections with portions of the frontal, parietal, temporal lobes, cingulate gyrus, basal nuclei, amygdala, and other structures of the limbic system and dorsal thalamus (Augustine, 1985, 1996). The richness of these connections lend support to its multiple role as a visceral sensory, visceral motor, motor association, vestibular, somatosensory, and language area. The insula has also been directly implicated in PET studies of emotion (Lane et al., 1997) and anxiety (Curtis, 1991). In particular, the region in the insula which was activated in our study was centred on the anterior insula. It has been suggested that the functional role of theanterior insula may participatein evaluating potentially distressing cognitive and interoceptive sensory information (Reiman et al., 1997; Reiman, 1997).

The anterior cingulate has been subdivided into areas specific for affect (Brodmann area 24, 25, 33) and cognition (Brodmann area 24' and 32') (Devinsky et al., 1995). The areas implicated in affect have extensive connections with the amygdala, periaqueductal grey, and autonomic brainstem motor nuclei (Devinsky et al., 1995). Lesion and functional neuroimaging studies have implicated the anterior cingulate in the modulation of autonomic activity and emotional responses. For example, in a conditioning experiment on rats whereby a neutral conditioning stimulus was paired with an aversive unconditioned response, i.e., footshock, lesions of the anterior cingulate cortex reduced the autonomic responses during the conditioning stimulus phase (Frysztak and Neafsey, 1991). The anterior cingulate and insula have also been implicated in previous imaging studies in pain (Derbyshire et al., 1994; Rainville et al., 1997; Howland et al., 1995). Rainville et al. (1997) used hypnotic suggestions to alter, selectively, the unpleasantness of the painful stimuli. The results revealed a modulation of pain-evoked activity in the anterior cingulate but not in the primary somatosensory cortex. This suggests a representation of the painful stimuli within the anterior cingulate which can be modified by cognitive means, i.e., hypnotic suggestions.

Regional specialization has also been reported within orbitofrontal cortex, which is divided into medial and lateral divisions by the medial orbital gyrus and olfactory groove (Morecraft et al., 1992), each division having connections with different paralimbic structures. It receives afferents from a diverse group of structures, including the hypothalamus, amygdala, hippocampus, olfactory cortex, midline and anterior thalamic nuclei, unimodal association areas, secondary somatosensory areas, and gustatory cortex. In this context, it is noteworthy that the left orbitofrontal cortex is activated when STAI scores are used as a covariate of interest. This suggests a possible role for this area in the "conscious" experience of anxiety given that the STAI consists of a series of statements about the subject's subjective experience. In a PET study of visualizing and perceiving aversive stimuli, it has been reported that $\mathrm{rCBF}$ increases in bilateral insula with negative, relative to neutral imagery but no such increases in comparison of negative and neutral perception (Kosslyn et al., 1996). The greater activation in the imagery conditions relative to the perception conditions suggest the insula may play a role in mental representation.

The evidence reviewed lends support to a proposal that anterior cingulate and insula have a role in mental representation of sensory and autonomic experience associated with anticipating painful electric shock. This is in line with Damasio's model of emotion, which he defined as a collection of changes in bodily and brain states in response to the content of one's thoughts relative to a particular entity and the experience of a particular cognitive mode (Damasio, 1995). Central to the model is the idea of representations of these bodily changes. The insula, anterior cingulate, and orbitofrontal cortex could conceivably act as the system through which sensory, autonomic, and cognitive information in relation to antici patory states are integrated and repre sented.

In view of the extensive literature on the role of the amygdala in fear and conditioning (Maren and Fansel ow, 1996; Morris et al., 1996), further analysis of the data examining for psychophysiological interactions between the insula and amygdala was performed but failed to find any interactional effects between these regions. The absence of the amygdala in the our study, and other studies of anxiety, may be explained by several factors. First, the time course of the amygdala response may be rapid with an attentuation of response that would not be resolved by PET (Breiter et al., 1996; Whalen et al., 1998). It has now been demonstrated that the amygdala response to fear-related contexts is time limited and, consequently, blocked experimental designs may be insensitive to regions which show profound time by condition interactions (Buchel et al., 1998). Second, while it is evident that the amygdala is important in recognition of fearful faces (Morris et al., 1996) and fear conditioning (Maren and Fanselow, 1996), fear and anxiety are not necessarily synonymous (Charney and Deutch, 1996; Barlow et al., 1996; Izard and Youngstrom, 1996). Fear is generally stimulusbound and temporally demarcated. Anxiety has similar features but is less stimulus-bound and is not closely bound in time to the actual stimulus. Third, in our study where the conditions were randomized, it is also possible that anxiety levels had not subsided sufficiently between scans. Indeed some subjects dem- 
onstrated a degree of anxiety related to the motor learning task. This may al so explain the lack of significant distraction effect in the motor learning task compared with the motor repetition task. Indeed, the psychological effects of distraction tasks during exposure to phobic stimuli can be ambiguous and in some, increases anxiety measures on reexposure to the stimulus (Rodriguez and Craske, 1993). A nonscanning pilot study on a different set of subjects had demonstrated that the level of anxiety could be reduced by using a motor learning task. Due to the large habituation effects in these type of paradigms, pilot data looking for a distraction effect was not specifically obtained on subjects involved in the scanning study prior to the scan. Fourth, failure to demonstrate an interaction between shock and learning may reflect the fact that similar structures, i.e., left insula, left orbitofrontal cortex, left anterior cingulate, demonstrated increased activity in the shock condition and motor learning conditions when considered individually. A final consideration to explain the lack of interaction between distraction and shock is that the neural responses to anticipatory anxiety may be obligatory in the sense that they are not influenced by other cognitive processes, i.e., the availability of attentional resources.

In summary, the main findings from this study indicate the importance of several paralimbic structures-namely the left insula, left anterior cingulate, and left orbitofrontal cortex-in the mediation of anticipatory anxiety in normal subjects. Of significance is the overlap of this finding with previous neuroimaging studies of anxiety disorders and suggests a common pathway in the functional neuroanatomy of pathological anxiety and the experience of anticipatory anxiety in normal subjects.

\section{ACKN O WLEDG MENTS}

Wethank Oliver J osephs and J ames Blair for their assistance with the collection and analysis of the GSR data. RJ D is supported by the Wellcome Trust.

\section{REFERENCES}

Augustine, J. R. 1985. The insular lobe in primates including humans. Neurol. Res. 7:2-10.

Augustine, J. R. 1996. Circuitary and functional aspects of the insular lobein primates including humans. Brain Res. Rev. 22:229244.

Azari, N. P., Pietrini, P., Horwitz, B., Pettigrew, K. D., Leonard, H. L., Rapoport, J . L., Schapiro, M. B., and Swedo, S. E. 1993. Individual differences in cerebral metabolic patterns during pharmacotherapy in obsessive-compulsive disorder: A multiple regression/ discriminant analysis of positron emission tomographic data. Biol . Psychiatry 34:798-809.

Barlow, D. H., Chorpita, B. F., and Turovsky, J . 1996. Fear, Panic, Anxiety, and Disorders of Emotion. Nebraska Symp. Motiv. 43:251328.

Baxter, L. R., Thompson, J . M., Schwartz, J . M., Guze, B. H., Phelps,
M. E., Mazziota, J . C., Selin, C. E., and Moss, L. 1987a. Trazodone treatment response in obsessive-compulsive disorder-correlated with shifts in glucose metabolism in the caudate nuclei. Psychopathol ogy 20(Suppl.1):114-122.

Baxter, L. R., Schwartz, J . M., Mazziota, J . C., Phelps, M. E., Pahl, J.J ., Guze, B. H., Fairbanks, L. 1988. Cerebral glucose metabolic rates in nondepressed patients with obsessive-compulsive disorder. Am. J . Psychiatry 145:1560-1563.

Baxter, L. R., Schwartz, J. M., Bergman, K. S., Szuba, M. P., Guze, B. H., Mazziota, J . C., Alazraki, A., Selin, C. E., Ferng, H. K., Munford, P., et al. 1992. Caudate glucose metabolic rate changes with both drug and behaviour therapy for obsessive-compulsive disorder. Arch. Gen. Psychiatry 49:681-689.

Baxter, L. R., Phelps, M. E., Mazziota, J . C., Guze, B. H., Schwartz, J . M., and Selin, C. E. 1987b. Local cerebral glucose metabolic rates in obsessive-compulsive disorder-compared to unipolar depression and normal controls. Arch. Gen. Psychiatry 44:211-218.

Benkelfat, C., Bradwejn, J., Meyer, E., Ellenbogen, M., Milot, S., Gjedde, A., and Evans, A. 1995. Functional neuroanatomy of CCK 4-induced anxiety in normal healthy volunteers. Am. J . Psychiatry 152(8): 1180-1184.

Breiter, H. C., Etcoff, N. L., Whalen, P. J ., Kennedy, W. A., Rauch, S. L., Buckner, R. L., Strauss, M. M., Hyman, S. E., and Rosen, B. R. 1996. Response and habituation of the human amygdala during visual processing of facial expression. Neuron 17(5):875887.

Buchel, C., Morris, J ., Dolan, R. J ., and Friston, K. J . 1998. Brain systems mediating aversive conditioning: An event-related fMRI study. Neuron 20(5):947-57.

Charney, D. S., and Deutch, A. 1996. A functional neuroanatomy of anxiety and fear: implications for the pathophysiology and treatment of anxiety disorders. Crit. Rev. Neurobiol. 10(3 \& 4):419-46.

Craske, M. G., and Street, L. L. 1991. Attention versus distraction during in vivo exposure: snake and spider phobias. J. Anxiety Disorders 5:199-211.

Curtis, G. C. 1991. PET findings in panic, anxiety, and phobic disorders. Ann. Clin. Psychiatry 3(2):111-4.

Damasio, A. R. 1995. Toward a neurobiology of emotion and feeling: Operational concepts and hypotheses. Neuroscientist 1(1):19-25.

Derbyshire, S. W. G., J ones, A. K. P., Devani, P., Friston, K. J ., Feinmann, C., Harris, M., Pearce, S., Watson, J. D. G., and Frackowiak, R. S. J . 1994. Cerebral responses to pain in patients with atypical facial pain measured by positron emission tomography. J . Neurol. Neurosurg. Psychiatry 57:1166-1172.

Devinsky, O., Morrell, M. J ., and Vogt, B. A. 1995. Contributions of anterior cingulate cortex to behaviour. Brain 118:279-306.

Drevets, W. C., Videen, T. O., MacLeod, A. K., Haller, J. W., and Raichle, M. E. 1992. PET images of blood flow changes during anxiety: correction. Science 256:1696.

Fredrickson, M., Wik, G., Greitz, T., Eriksson, L., Stone-Elander, S., Ericson, K., and Sedvall, G. 1993. Regional cerebral blood flow during experimental phobic fear. Psychophysiology 30:126-130.

Fredrikson, M., Wik, G., Annas, P., Ericson, K., and Stone-Elander, S. 1995. Functional neuroanatomy of visually elicited simple phobic fear: Additional data and theoretical analysis. Psychophysiology 32:43-48.

Frysztak, R. J ., and Neafsey, E. J . 1991. The effect of medial frontal cortex lesions on respiration, 'freezing,' and ultrasonic vocalisations during conditioned emotional responses in rats. Cerebral Cortex 1:418-425.

Gray, J. A., and McNaughton, N. 1996. The Neuropsychology of Anxiety:Reprise. Nebraska Symp. Motivation 43:61-134.

Gur, R. C., Gur, R. E., Skolnick, B. E., Resnick, S. M., Silver, F., Chawluk, J ., Muenz, L., Obrist, W. D., and Reivich, M. 1988. Effects 
of task difficulty on regional cerebral blood flow:relationships with anxiety and performance. Psychophysiology 25:392-399.

Gur, R. C., Gur, R. E., Resnick, S. M., Skolnick, B. E., Alavi, A., and Reivich, M. 1987. The effect of anxiety on cortical cerebral blood flow and metabolism. J . Cerebral Blood Flow Metab. 7(2):173-7.

Horwitz, B., Swedo, S. E., Grady, S. E., Pietrini, P., Shapiro, M. B., Rapoport, J. L., and Rapoport, S. I. 1991. Cerebral metabolic pattern in obsessive-compulsive disorder: altered intercorrelations between regional rates of glucose utilisation. Psychiatry Res. Neuroimag. 40:221-237.

Howland, E. W., Wakai, R. T., Mjaanes, B. A., Balog, J. P., and Cleeland, C. S. 1995. Whole head mapping of magnetic fields following painful electric finger shock. CognitiveBrain Res. 2:165172.

Izard, C. E., and Youngstrom, E. A. 1996. The Activation and Regulation of Fear and Anxiety. Nebraska Symp. Motivation 43:159.

J ueptner, M., Stephan, K. M., Frith, C. D., Brooks, D. J ., Frackowiak, R. S. J ., Passingham, R. E. 1997. Anatomy of motor learning. I. Frontal cortex and attention to action. J . Neurophysiol. 77:13131324.

Kosslyn, S. M., Shin, L. M., Thompson, W. L., McNally, R. J ., Rauch, S. L., Pitman, R. K., and Alpert, N. M. 1996. Neural effects of visualising and perceiving aversive stimuli: A PET investigation. Neuroreport 7:1569-1576.

Lane, R. D., Fink, G. R., Chua, P. M. L., and Dolan, R. J . 1997. Neural activation during selective attention to subjective emotional re sponses. Neuroreport 8:3969-3972.

Maren, S., and Fanselow, M. S. 1996. The Amygdala and Fear Conditioning: Has the nut been cracked? Neuron 16:237-240.

Martinot, J . L., Allilaire, J . F., Mazoyer, B. M., Hantouche, E., Huret, J . D., Legaut-Demare, F., Deslauriers, A. G., Hardy, P., Pappata, S., Baron, J . C., et al. 1990. Obsessive-compulsive disorder: a clinical, neuropsychological and positron emission tomography study. Acta Psychiatria Scand. 82:233-242.

McGuire, P. K., Bench, C. J ., Frith, C. D., Marks, I. M., Frackowiak, R. S. J ., and Dolan, R. J . 1994. Functional anatomy of obsessivecompulsive phenomena. Br. J . Psychiatry 164:459-468.

Mesulam, M. M., and Mufson, E. J . 1982. Insula of the old world monkey. I: Architectonics in the insulo-orbito-temporal component of the paralimbic brain. J . Comp. Neurol . 212:1-22.

Morecraft, R. J ., Geula, C., and Mesulam, M. M. 1992. Cytoarchitecture and neural afferents of orbitofrontal cortex in the brain of the monkey. J . Comp. Neurol. 323:341-358.

Morris, J . S., Frith, C. D., Perrett, D. I., Rowland, D., Young, A. W., Calder, A. J ., and Dolan, R. J . 1996. A differential neural response in the human amygdala to fearful and happy facial expressions. Nature 383:812-815.

Mountz, J. M., Modell, J . G., Wilson, M. W., Curtis, G. C., Lee, M. A., Schmaltz, S., and Kuhl, D. E. 1989. Positron Emission Tomographic Evaluation of cerebral blood flow during state anxiety in simple phobia. Arch. Gen. Psychiatry 46:501-504.

Nordahl, T. E., Semple, W. E., Gross, M., Mellman, T. A., Stein, M. B., Goyer, P., King, A. C., Uhde, T. W., and Cohen, R. M. 1990. Cerebral glucose metabolic differences in patients with panic disorder. Neuropsychopharmacology 3(4):261-272.

Nordahl, T. E., Benkelfart, L., Semple, W. E., Gross, M., King, A. C., and Cohen, R. M. 1989. Cerebral glucose metabolic rates in obsessive-compulsive disorder. Neuropsychopharmacology 2:2328.

O'Carroll, R. E., M offort, A. P. R., Van Beck, M., Dougall, N., Murray, C., Ebmeier, K. P., and Goodwin, G. M. 1993. The effect of anxiety induction on the regional uptake of 99mTc-Exametazime in simple phobia as shown by single photon emission tomography(SPET). J . Affec. Disord. 28:203-210.
Perani, D., Colombo, C., Bressi, S., Bonfanti, A., Grassi, F., Scarone, S., Bellodi, L., Smeraldi, E., Fazio, F. 1995. [18F ]F DG PET Study in obsessive-compulsive disorder. A clinical/metabolic correlation study after treatment. Br. J . Psychiatry 166:244-250.

Rainville, P., Duncan, G. H., Price, D. D., Carrier, B., Bsuhnell, M. C. 1997. Pain affect encoded in human anterior cingulate but not somatosensory cortex. Science 277:968-971.

Rauch, S., Savage, C. R., Alpert, N. M., Miguel, E. C., Baer, L., Breiter, H. C., Fischman, A. J ., Manzo, P. A., Moretti, C., and J enike, M. A. 1995. A positron emission tomographic study of simple phobic symptom provocation. Arch. Gen. Psychiatry 52: 20-8.

Rauch, S. L., J enike, M. A., Alpert, N. M., Baer, L., Breiter, H. C. R., Savage, C. R., Fischman, A. J . 1994. Regional cerebral blood flow measured during symptom provocation in obsessive-compulsive disorder using oxygen15-labeled carbon dioxide and positron emission tomography. Arch. Gen. Psychiatry 51:62-70.

Rauch, S. L., Savage, C. R., Alpert, N. M., Fischman, A. J ., and J enike, M. A. 1997. The functional neuroanatomy of anxiety: A study of three disorders using positron emission tomography and symptom provocation. Biol. Psychiatry 42:446-452.

Reiman, E. M. 1987. The study of panic disorder using positron emission tomography. Psychiatric Dev. 1:63-78.

Reiman, E. M., Raichle, M. E., Robins, E., Mintun, M., Fusselman, M. J ., Fox, P. T., Price, J . L., and Hackman, K. A. 1989. Neuroanatomical correlates of a lactate-induced anxiety attack. Arch. Gen. Psychiatry 46:493-500.

Reiman, E. M. 1997. The application of positron emission tomography to the study of normal and pathologic emotions. J. Clin. Psychiatry 58(Suppl. 16):4-12.

Reiman, E. M., Lane, R. D., Ahern, G. L., Schwartz, G. E., Davidson, R. J ., Friston, K. J ., Yun, L. S., and Chen, K. 1997. Neuroanatomical correlates of externally and internally generated human emotion. Am. J . Psychiatry 154:918-925.

Reiman, E. M., Fusselman, M. J ., Fox, P. T., and Raichle, M. E. 1989. Neuroanatomical correlates of anticipatory anxiety. Science 243: 1071-1074.

Reiman, E. M., Raichle, M. E., Butler, F. K., Herscovitch, P., and Robins, E. 1984. A focal brain abnormality in panic disorder, a severe form of anxiety. Nature 23:683-685.

Reivich, M., Alavi, A., Gur, R. C. 1984. Positron Emission Tomographic studies of perceptual tasks. Ann. Neurol. 15(Suppl.):S61S65.

Rodriguez, B. I., and Craske, M. G. 1993. The effects of distraction during exposure to phobic stimuli. Behav. Res. Ther. 31:459-558.

Rodriguez, G., Cogorno, P., Gris, A., Marenco, S., Mesiti, C., N obili, F., and Rosadini, G. 1989. Regional cerebral blood flow and anxiety: A correlation study in neurologically normal patients. J. Cerebr. Blood Flow Metab. 9:410-416.

Swedo, S. E., Schapiro, M. B., Grady, C. L., Cheslow, D. L., Leonard, H. L., Kumar, A., Friedland, R., Rapoport, S. I ., and Rapoport, J . L. 1989. Cerebral glucose metabolism in childhood-onset obsessivecompulsive disorder. Arch. Gen. Psychiatry 46:518-523.

Talairach, J., and Tournoux, P. 1988. Co-Planar Stereotaxic Atlas of theHuman Brain. Thieme, New York.

Whalen, P. J ., Rauch, S. L., Etcoff, N. L., Mcl nerney, S. C., Lee, M. B., J enike, M. A. 1998. Masked presentations of emotional facial expressions modulate amygdala activity without explicit knowledge. J . Neurosci. 18(1):411-418.

Wik, G., Fredrickson, M., Ericson, K., Eriksson, L., Stone-Elander, S., and Greitz, T. 1993. A functional cerebral response to frightening visual stimulation. Psychiatry Res. Neuroimag. 50:15-24. 